\title{
Covid - 19: o papel dos conselhos gestores de saúde na accountability
}

\section{Covid - 19: the role of health management councils in accountability}

DOI: $10.46919 / \operatorname{archv} 2 n 3-004$

Recebimento dos originais: 01/05/2021

Aceitação para publicação: 30/06/2021

\section{Hermes Oliveira Gomes}

Mestre em Propriedade Intelectual e Transferência de Tecnologia para a Inovação na Universidade

Federal da Bahia -UFBA

Endereço: Av. Reitor Miguel Calmon. s/n. Vale do Canela. Salvador. 40110-902. ICS -UFBA

E-mail: hermes.oliveira@ufba.br

\section{Magno Oliveira Ramos}

Mestre em Contabilidade na Universidade Federal da Bahia -UFBA

Endereço: Av. Reitor Miguel Calmon. s/n. Vale do Canela. Salvador. 40110-902. Faculdade de Ciências

Contábeis -UFBA

E-mail: magnusso1@yahoo.com.br

\section{Maria Valesca Damásio Carvalho Silva}

Doutora em administração na Universidade Federal da Bahia -UFBA

Endereço: Av. Reitor Miguel Calmon. s/n. Vale do Canela. Salvador. 40110-902. Faculdade de Ciências

Contábeis -UFBA

E-mail: mvalesca.ufba@gmail.com

\section{RESUMO}

Em um momento que a saúde pública está em evidência, muito motivada pela atual pandemia do COVID 19, retomar as discussões sobre a importância dos conselhos gestores e seu papel de fiscalização e controle dos recursos destinado a saúde pública torna-se importante. Assim o objetivo do artigo a apresentar um olhar epistemológico sobre o papel dos conselhos na fiscalização dos recursos destinado a saúde pública brasileira. Como metodologia, usou-se uma abordagem exploratória qualitativa, com estudo bibliográfico e documental. Os resultados apontam que os conselhos se mostram de extrema importância, não só no papel de agente de fiscalização, mais também como formuladores de políticas e ações sociais a serem implementadas. Assim em meio a essa pandemia do COVID -19, a atuação dos conselhos deve ser mais presentes, permitindo promover políticas públicas para quem mais precisa, bem como evitando possíveis desvios de recursos públicos.

Palavras-chave: COVID -19, Conselhos Gestões de Saúde, Contas Públicas

\begin{abstract}
At a time when public health is in evidence, highly motivated by the current pandemic of COVID -19, resuming discussions on the importance of management councils and their role of overseeing and controlling resources for public health becomes important. Thus, the objective of the article is to present an epistemological look at the role of councils in the inspection of resources destined to Brazilian public health. As a methodology, a qualitative exploratory approach was used, with bibliographic and documentary study. The results show that the councils are extremely important, not only in the role of inspection agent, but also as formulators of policies and social actions to be implemented. Thus, in the midst of this COVID -19
\end{abstract}


pandemic, the work of the councils should be more present, allowing to promote public policies for those who need it most, as well as avoiding possible diversion of public resources.

Keyword: COVID -19, Health Management Councils, Public Accounts

\section{INTRODUÇÃO}

Participação popular na construção das políticas e no fortalecimento da gestão pública no Brasil é algo que sempre existiu, no entanto, os processos de participação cidadã na política brasileira demarca-se em pontos de tendência antes do período militar (1964 -1985) e pós esse período. Mas, de forma explícita, as discussões sobre o surgimento dos conselhos gestores no Brasil ligam-se à promulgação da Constituição Federal de 1988, que de forma concreta tornou a temática formal e de suma importância para transformar o campo das políticas públicas participativa no Brasil.

Na verdade, é possível afirmar que os conselhos gestores ganharam forma a partir dos anos 80 sendo importantes porque "são frutos de demandas populares e de pressões da sociedade civil pela redemocratização do país”, (GOHN, 2002, p.13), sendo representado por movimentos sociais que exercem um papel significativo nesse processo de construção e de transformação desses conselhos.

Destaca-se que atualmente a atuação dos conselhos no processo da gestão colaborativa é quase uma imposição constitucional, haja vista a necessidade e exigência legal de repasses dos recursos federais às demais esferas (estadual e municipal), mediante a estrutura e funcionamento de um conselho. Estes órgãos passaram a dar suporte nos processos de formulação, fiscalização, e aplicação de recursos públicos.

Ao revisar a literatura sobre a definição de Conselho Gestor encontra-se um número significativo de termos, que em partes comungam de uma similitude, entendida como a participação do povo na gestão pública. Nessa linha, pode definir conselho gestor como uma forma de organização política administrativa que possibilita a participação do povo na gestão das políticas públicas, se configurando como órgão administrativo e fiscalizatório sendo composto por representantes da sociedade civil e poder público (TERRA, 2020)

Conselho também pode ser entendido como um conglomerado de entes públicos, privados, representantes do terceiros setor, entre outros representantes sociais, destinado a encontrar soluções sobre pautas sociais de conhecimento e interesse comum aos entes envolvidos, tendo finalidade e função definida conforme lei e decretos de formação, além dos próprios quesitos basilares definido em carta magna.

Define-se conselhos também como uma rede interinstitucional de órgãos, entidades e representantes sociais, destinado a prestar suporte a administração direta na gestão pública, em prol de um bem público comum e específico. 
Nessa linha, o caminho de leitura agenciado nesse texto tem por objetivo apresentar uma discursão teórica e situacional sobre a importância dos conselhos na fiscalização das contas públicas, especialmente agora na eminência do coronavírus (covid1-19). Assim, este estudo teve como motivação a importância que tem os conselhos na fiscalização dos recursos públicos destinados a saúde, bem como a relevância que esse tema tem em relação aos recursos que vem se destinando ao enfrentamento da pandemia.

A delimitação do escopo desta pesquisa deu-se também pelo fato da obrigatoriedade dada pelo ministério da saúde, ao exigir a criação de conselho de saúde para legitimar e fiscalizar os repasses federais de recursos públicos para saúde em todas as esferas da administração pública.

Desta forma, percebe-se que os Conselhos Gestores, a exemplo dos conselhos de saúde, funcionam como espaços de controle social importantes para o fortalecimento e ampliação da democracia, bem como o exercício dos princípios da participação popular, uma vez que legitima as ações dos órgãos aos quais estão vinculados, deliberando por reivindicações feitas em cada reunião de conselho.

Neste sentido, as audiências públicas, assim como os conselhos, mostram-se de fundamental importância no que diz respeito à garantia de participação da população no debate político e na fiscalização para além da estrutura legislativa e executiva na gestão do território.

Além disso, quando se pensa no pressuposto de que tudo que o governo gasta origina-se dos impostos e taxas, saber sobre os gastos e investimentos é um dever e obrigação dos cidadãos, enquanto contribuintes. Nesse contexto, observa-se a importância de avaliar os mecanismos de controle e de participação cidadã, perante administradores públicos e em especial sobre a ótica dos conselheiros, que têm o direito e dever de realizar a fiscalização dos gastos e aplicação de recursos públicos.

Com os impostos federais pagos, a instância federal obriga-se a repassar verbas destinadas a realizar diversas ações sobre competência administrativa e distributiva do poder executivo municipal. Desta forma, fica para o governo federal, estados e as prefeituras a contrapartida de planejar e realizar os gastos, como também transparecer à população sobre realização dos mesmos, conforme a Lei de Responsabilidade Fiscal (BRASIL, 2001, Art.48 e 49).

Por conseguinte, observa-se que, nos mecanismos de controle da execução dos gastos estatuais e municipais, encontra-se o poder legislativo como o principal mecanismo de acompanhamento da execução orçamentária. Esses legisladores, eleitos pelo povo, têm a atribuição de fiscalizar o executivo sobre a realização de despesas, com o auxílio dos conselhos e sociedade.

Em segundo plano, os conselhos municipais mostram-se como um grande aliado do poder executivo na implementação das políticas públicas, e um forte parceiro da câmara de vereadores na fiscalização e observância das aplicações desses recursos. E, neste sentido, temos a área da saúde como sendo uma das mais importantes e fundamentais das áreas sociais, afinal, trata-se de recursos aplicados e movimentados na saúde pública, imprescindível à sobrevivência humana da sociedade, o que está preconizado na própria 
Constituição Federal de 1988, em seu Art. $6^{\circ}$ que versa: "São direitos sociais a educação, a saúde, a alimentação, o trabalho, a moradia, o lazer, a segurança, a previdência social, a proteção à maternidade e à infância, a assistência aos desamparados, na forma desta Constituição".

Assim, ver-se que com o assolamento da crise de saúde pública mundial causada pela COVID-19 exigem mais responsabilidade do poder legislativo e conselheiros de saúde, uma vez que as ações e os gastos do poder executivo obtivem maiores flexibilizações enquanto a dispensa de licitações e descumprimento de orçamento previamente apresentado. Observa-se também que a má aplicação e gestão dos recursos na área de saúde resultarão em um caos social significativo, como ausência de leitos, enfermarias, postos de saúde, medicamentos, quanto dos óbitos ocasionados por inteira falta de atendimento.

Parte desta má aplicação de recursos dá-se pela falta de conhecimento e capacitação do poder legislativo e dos membros conselheiros de saúde eleitos, nomeados e ou indicados. Essa falta de conhecimento faz com que estes agentes não tomem as decisões acertadas a fim de garantir a melhor afetividade na fiscalização dos recursos.

Diante da contextualização apresentada acima, o problema de pesquisa partiu da seguinte questão:

Qual o papel dos conselhos na fiscalização dos recursos na área de saúde, especificamente no enfrentamento do covid 19.

O desenvolvimento local inicia-se pela saúde do seu povo, diante disso, pretende-se com estudo oferecer maiores subsídios para que os recursos públicos direcionados a saúde, cheguem de fato ao seu destino. Mas, para que isso aconteça, será necessário que os conselheiros gestores tenham o adequado entendimento das contas públicas e se as mesmas estão em conformidade com o planejado. Assim, economicamente, a pesquisa trará um impacto direto, pois, se os recursos forem adequadamente alocados, ter-se-á na gestão pública, eficiência, eficácia, efetividade e economicidade dos recursos financeiros. Desta forma, a fiscalização e a tomada de decisão a respeito das políticas e recursos aplicados devem ser feitas com clareza pelos conselheiros gestores. Uma vez inadequadamente administrados, os recursos públicos, dificilmente poderão atender as necessidades públicas na sua totalidade, ainda mais agora com a pandemia do COVID-19 instalada.

Tratar da temática em torno dos conselhos gestores, principalmente os da saúde, é uma possibilidade de contribuir fundamentalmente à área social, afinal, por envolver recursos aplicados e movimentados na saúde pública, imprescindíveis à sobrevivência humana da sociedade, o que está preconizado na própria Constituição Federal de 1988, em seu Art. 6º . Ou seja, se os conselhos gestores conseguem realizar com efetividade a observância desses princípios básicos e aplicação correta dos recursos a eles destinados, como se propõe essa pesquisa, logicamente teremos uma sociedade mais assistida socialmente. 


\section{METODOLOGIA}

Essa pesquisa é considerada exploratória por trazer diferentes fontes ao tema em estudo; descritiva por narrar os achados da pesquisa e explicativa, ao analisar e interpretar os dados evidenciados no estudo. Diante disso, usou-se da pesquisa exploratória, por meio de fontes bibliográficas e documentais como livro, artigos, normas e atos normativos relacionadas ao tema. (GIL, 2002)

Para realização da pesquisa, usou-se de um estudo bibliográfico com leitura de artigos, mais relacionados com conselhos gestores de saúde, seguindo de levantamento documental de Leis e decretos que ampara a temática, e por fim, análise a descrição dos achados.

Para tanto usou-se o portal periódico capes como fonte principal de busca para os artigos, além disso foi usado a ferramenta do Google acadêmicos como mecanismo de busca. Tendo como primeira estratégica de seleção o uso de palavras chave, conselhos gestores, coronavírus, COVID-19, corrupção, seja em português ou inglês, seguida de uma leitura inicial de seus resumos.

\section{OBJETO ECONÔMICO E FINANCEIRO DA FISCALIZAÇÃO DOS CONSELHOS}

Em termos econômico e financeiro, os conselheiros têm um papel fundamental na fiscalização sobre aplicação e gastos dos recursos públicos, no caso em questão, principalmente os da saúde, no que refere ao SUS (Sistema Único de saúde). Segundo a Lei 8142/90 no artigo $1^{\text {º: }}$

\footnotetext{
O sistema único de saúde - SUS de que trata a lei nº 8.080, de 19 de setembro de 1990, contará, em cada esfera de governo, sem prejuízo das funções do poder legislativo, com as seguintes instâncias colegiadas: i - a conferência de saúde, e; ii - o conselho de saúde.
}

Em seguida, no parágrafo $\S 2^{\circ}$, há uma definição do conceito de conselho de saúde, bem como de suas atribuições:

\footnotetext{
O conselho de saúde, em caráter permanente e deliberativo, órgão colegiado composto por representantes do governo, prestadores de serviço, profissionais de saúde e usuários, atua na formulação de estratégias e no controle da execução da política de saúde na instância correspondente, inclusive nos aspectos econômicos e financeiros, cujas decisões serão homologadas pelo chefe do poder legalmente constituído em cada esfera do governo (BRASIL, LEI 8142/90).
}

Neste sentido, os conselhos de saúde municipal têm como objetivo acompanhar os projetos e ações relativas à saúde local no município, controlando e fiscalizando o bom uso dos recursos e a democratização dos investimentos. Contudo, observa-se que, para uma boa gestão dos recursos na área de saúde, exige-se dos conselheiros um maior entendimento sobre a seara dos assuntos relativos às contas públicas. Assim o manual de orientações do Ministério da Saúde define e apresenta o real papel dos conselheiros, a partir da seguinte perspectiva. 
O Conselho Municipal de Saúde deve discutir e aprovar o Plano Municipal de Saúde (PMS), o Relatório de Gestão Anual (RGA), as prestações de contas e, ainda, discutir e apreciar diretrizes para as políticas, programas e ações que serão implementadas no município. É necessário existir uma rotina mínima para os Conselhos que é sua importante participação na elaboração dos planos e em seu acompanhamento, inclusive nos aspectos econômicos e financeiros. O grande impasse dos conselhos é justamente quando desconhecem sua dupla missão de ajudar a fazer e aprovar o plano, assim como acompanhar e controlar econômica e financeiramente este plano, objeto principal do controle social. Para exigirmos eficiência e eficácia das ações e serviços de saúde nos municípios devemos ser coautores da principal ferramenta que detém essas informações que é o plano de saúde, além de acompanhá-lo, avalia-lo monitorando-o constantemente. (BRASIL. CONASEMS ${ }^{1}, 2009$ ?).

Assim, para maior evidenciação do fluxo processual de fiscalização e importância dos conselheiros sobre a gestão dos recursos públicos em saúde, apresenta-se a figura 1 abaixo:

Figura 1 - Fluxograma processual sobre sobre as relaçoes e processos burocraticos nos tramites da gestao dos recursos do SUS nos municipios

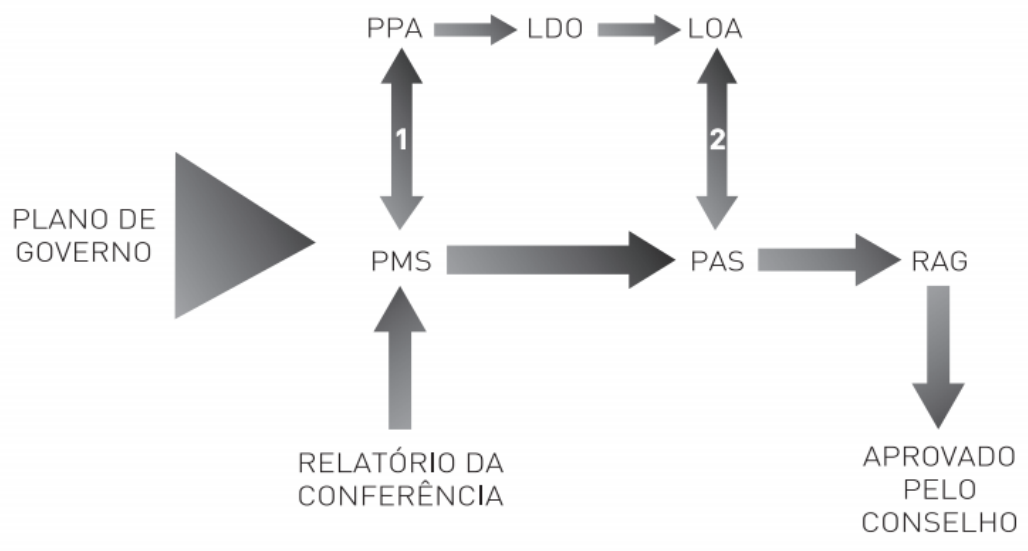

Fonte: Brail. Conasems, 2009

Todas as discussões e projetos para a saúde pública do município iniciam-se nos ambientes denominados como Conferências Municipais de Saúde (CMS), normalmente no primeiro ano da gestão municipal, cujo objetivo é a produção de um relatório que comporá o Plano Municipal de Saúde (PMS). Além disso, mesmo esse material sendo considerado de caráter genérico, ele é basilar para compor o Planejamento Plurianual (PPA) e a Programação Anual de Saúde (PAS) no município, tendo como a supervisão e parâmetros a Lei de Diretrizes Orçamentaria (LDO) e Lei Orçamentaria Anual (LOA). E, por conseguinte, o Relatório Anual de Gestão (RAG), que sintetiza uma avaliação das metas e do desempenho econômico financeiro de todas as ações executadas, não só pela gestão municipal.

O papel do conselho é fundamental neste ordenamento lógico, tanto como fomentador das políticas e demandas no ambiente da conferência, quanto na supervisão e avaliação do cumprimento da PPA, LDO e LOA e, em seguida, na aprovação do Relatório Anual da Gestão (RAG).

\footnotetext{
${ }^{1}$ Conselho Nacional de Secretários Municipais de Saúde
} 


\subsection{FORMAS DE TRANSFERÊNCIA DOS RECURSOS FEDERAIS PARA A SAÚDE}

Importante ressaltar que os recursos federais destinados aos municípios são resultantes do Plano Municipal de Saúde em concordância com o Plano Nacional de Saúde. Desta forma, têm-se assim três tipos de fontes de recursos: as transferências regulares e automáticas por meio de fundos; remuneração por meio de serviços produzidos; e convênios, contratos de repasses e outros instrumentos similares.

Segundo Andrade (2006, p. 186), o Fundo Municipal de Saúde é um instrumento de planejamento por permitir ao gestor, o conhecimento dos recursos de que dispõe para as ações e serviços de saúde, o controle por facilitar o acompanhamento permanente sobre as fontes de receitas, seus valores e datas de ingresso, as despesas realizadas e os rendimentos de aplicações financeiras.

São nas contas especiais do Fundo Municipal de Saúde que se depositam e movimentam-se os recursos financeiros do sistema sob a fiscalização do Conselho de Saúde (artigo 33 da Lei 8.080/90 e incisos I e V do artigo $4^{\circ}$ da Lei 8.142/90 e Lei Complementar 141/2012).

Nesta modalidade de repasse, o objetivo é repassar pagamento de forma direta aos profissionais cadastrados no sistema, por prestar atividades ambulatoriais e serviços hospitalares. Assim, destaca-se a possibilidade de repasse a instituições privadas que prestam serviços públicos de saúde e estejam devidamente cadastradas.

Os Convênios representam tipos de acordos específicos entre a União/Ministério da Saúde com os estados e municípios, ou mesmo com entidades filantrópicas e organizações não governamentais, para financiamento de projetos não contemplados nos planos e projetos já aprovados nas instâncias deliberativas.

Todo convênio deve apresentar um Plano de Trabalho que informe quando e como devem ser executadas as ações. O repasse do dinheiro, ao longo do convênio, é feito com base no cronograma físicofinanceiro que faz parte do Plano de Trabalho e, também, com base na disponibilidade financeira de quem dá o dinheiro (concedente). O dinheiro repassado por meio de convênio não pode ser utilizado para finalidade diferente daquela que foi prevista no convênio (BRASIL, TCU, ORIENTAÇÕES PARA CONSELHEIROS DE SAÚDE. 2010).

Em Saúde, a prestação de conta deve ser obrigatória, seja ela originária de recursos de Convênio e/ou do Fundo Municipal de Saúde. A primeira fonte, os gestores devem prestar conta ao Ministério de Saúde; e a segunda, as contas devem ser apreciadas pelos Conselheiros Gestores, Câmera de Vereados e Tribunal de Contas.

\subsection{LIMITES E EXIGÊNCIAS CONSTITUCIONAIS COM SAÚDE NO MUNICÍPIO}

A reforma sanitária, um dos legados da Constituição de 1988, consistiu em um avanço capital, no que diz respeito, à participação social nos conselhos de saúde e sua dinâmica de funcionamento. Entretanto, muito há o que se observar no âmbito desse espaço de discussão, sobretudo, em relação aos recursos 
financeiros que deveriam ser aplicados na implementação de políticas públicas de saúde. Para as estimativas de gastos, por força da Emenda Constitucional n. ${ }^{\circ} 29$, de 13 de setembro de 2000 (que alterou os artigos 34, 35, 156, 160 e 198 da Constituição Federal e acrescentou o artigo 77 ao Ato das Disposições Constitucionais Transitórias) aos Municípios e ao Distrito Federal, fixou-se para o ano de 2000, o gasto mínimo por município em 7\% (sete por cento) da receita vinculável.

Segundo Andrade (2006, p. 183), “Antes da promulgação da emenda Constitucional n 29, não havia nenhuma legislação federal que exigisse a aplicação de percentual mínimo na saúde [...]”, no entanto, essa realidade em alguns municípios, já era consolidada na Lei Orgânica Municipal, segundo o autor, mesmo sabendo da necessidade de novas formulações.

Já a partir da Lei complementar n $n^{\circ} 141$ de 13 de janeiro de 2012, regularizou e atualizou os valores mínimos a serem aplicados mensalmente, estabelecendo critérios de rateio dos recursos de transferência para a saúde e as normas de fiscalização, avaliação e controle das despesas com saúde, seja na União, Estados e Municípios.

Tendo os municípios como objeto de estudo, a Lei 141/12 determina que os municípios tenham a obrigação de aplicar 15\% da arrecadação dos impostos, em específico os inscritos no Art. 156 da mesma Lei, como: propriedade predial e territorial urbana; transmissão "inter vivos", a qualquer título, por ato oneroso, de bens imóveis, por natureza ou acessão física, e de direitos reais sobre imóveis, exceto os de garantia, bem como cessão de direitos a sua aquisição; e serviços de qualquer natureza.

\subsection{TEORIA DO AGENTE SOBRE O ENFOQUE DOS CONSELHOS GESTORES}

Na própria lei 8142/90 no Artigo 1º $, \S 4:$ “A representação dos usuários nos Conselhos de Saúde e Conferências será paritária em relação ao conjunto dos demais segmentos." Neste sentido, os conselhos de saúde são obrigatoriamente constituídos por $25 \%$ de membros de governo, 25\% de membros usuários, 25\% prestadores de serviços, e os outros $25 \%$ por organizações representativas da sociedade civil organizada.

Assim, de um lado temos os representantes do poder público, exercendo a função de "agente" e, por outro lado, um coletivo social exercendo função do "principal". Nota-se, com isso que, por muitas vezes, o agente não exerce suas atribuições com o intuito de satisfazer as necessidades do principal. Isso remete a problemas denominados de conflito de interesses, em que as partes divergem sobre os princípios e objetivos das relações contratuais.

É nesta necessidade de paridade e democratização da composição dos conselhos que surgem as questões de conflito de interesses entre as classes de representantes e representadas. Mesmo tendo um objetivo em comum (no caso a saúde pública), os grupos representativos, tendem a buscar benefícios e ações que, porventura, venham beneficiar direta ou indiretamente seus representados. Assim, é importante 
destacar que os membros dos conselhos, independentes de suas corporações (de governo, de gestores, de profissionais, de prestadores, de usuários, de sociedade civil organizada,) devem representar o coletivo.

Segundo (BRASIL. CONASEMS, 2009? p.22), ressalta que os espaços dos conselhos "Trata-se sem dúvida de uma arena constante de conflitos, mas que não deve ser encarado como espaço de discórdias e dissenso ou apenas de crítica e de desqualificação da gestão".

O gestor deve ter claro que o espaço do Conselho não é de oposição político partidária e nem tão pouco apenas de reivindicações trabalhistas/salariais ou corporativistas, mas sim, um espaço de debate aberto das questões que permeiam a política de saúde e sua gestão local. (BRASIL. CONASEMS, 2009? p.22)

Craco e Almeida (2004, p. 191), em seus estudos sobre os conselhos, observaram que as relações e ambientes das plenárias dos conselhos tornavam-se literalmente uma "conversa de surdos e cegos", em meio a muitas interações autoritárias e violentas e posturas agressivas, as peças do quebra-cabeça não se encaixavam de forma alguma, cada sujeito ficava isolado e preso em seus interesses específicos e não se abria para ver e escutar (acolher) o outro tinha a dizer, estabelecendo assim, mais um "monólogo" do que um "diálogo", onde o outro não era visto nem escutado.

No cerne da discursão sobre informações contábeis, Hendriksen e Van Breda (1999) e Scott (1941) entendem que toda informação deve atender aos princípios de justiça, equidade e verdade de forma contribuir para o aumento do bem-estar de todos. Desta maneira, percebe-se que o acesso e entendimento das informações contábeis, por muitas vezes, não se faz entendida, e muito pelo contrário, dificulta o entendimento da real situação das contas públicas.

Correia (2002) apud Salibas et al (2009, p.1376) afirma que o controle social sobre os recursos públicos ainda construí um desafio para os conselheiros, destacando duas razoes: a primeira pauta-se pela perspectiva de submissão sobre as questões técnicas e especificas, em que atribui-se apenas de competência para administradores e técnicos públicos. A segunda atribui os mecanismos de prestação de contas com algo complexo, o que dificulta a compreensão.

Assim Abers (2002) apud Salibas et al (2009, p.1376) observa que o controle social dos representantes dos usuários sobre as contas do gestor tem sido a meta mais difícil de ser alcançada em quase todos os conselhos de saúde.

Trabalho como o Labra e Figueredo (2002, p.543) chegou à constatação que os principais meios de informação dos conselheiros, correspondiam: a televisão e jornais (88\%); amigos, radio e família (66\%); e revista e livros (46\%). Assim nota que falta a disponibilidade de fontes técnicas de informação, podendo comprometer a qualidade da tomada de decisão mais acertada.

Silaba et al (2009) através de sua pesquisa com 36 conselheiros em Araçatuba, no Estado de São Paulo em 2007 contatou que : 
Quanto ao grau de instrução, 71,5\% dos entrevistados não possuem ensino superior completo, o que possivelmente tem dificultado na compreensão de documentos. No segmento dos usuários, a maioria possui ensino fundamental incompleto. Com relação ao meio de ingresso no conselho, apenas $19 \%$ ingressaram por meio de eleição, $61 \%$ dos conselheiros foram indicados, 9,5\% nomeados e 9,5\% ingressaram de outra forma. Do total de entrevistados inicialmente, $50 \%$ relataram que há falta de informações importantes que poderiam auxiliar o conselheiro a melhorar seu desempenho. Depois do curso, a proporção aumentou para $61,1 \%$, talvez pelo fato de eles terem tomado conhecimento de vários decretos, leis e outros documentos até então desconhecidos. Dos conselheiros de saúde, $70 \%$ não sentem dificuldade em analisar documentos, relatórios e orçamentos. Do total de entrevistados, 54,8\% nunca participaram de discussão sobre orçamento.

Trabalhos como os de Wendhausen e Caponi (2002) e Silaba et al (2009) demostram em seus achados de pesquisas que os conselheiros com escolaridade de ensino superior completo entra-se nos segmentos compostos por representante de órgão público, seguindo dos profissionais de saúde e prestadores de serviço, ou seja, por muitas vezes as possibilidades de argumentação e reflexão sobre termos e assuntos de saúde são em maior frequência abordados por este tipo grupo de profissionais.

Por fim Saliba et al (2009) conclui em seus achados, entendendo que uma possível mudança de percepção e compreensão das funções dos conselheiros nos desenvolvimentos de suas atividades, partir da implementação de cursos de capacitação, pode transformar a realidade social em algo mais prospero.

Martins et al (2008) destaca que essa falta de conhecimento de alguns membros dos conselhos tem sido muitas vezes utilizada por alguns gestores como pretexto e justificativa para reforçar a imagem que os representantes dos usuários são tecnicamente e socialmente despreparados para jugar as contas públicas e tomar decisões na área de saúde.

Algumas pesquisas aponta a importância que as universidades podem promover na promoção de capacitação desde conselheiros, sejam em instituições de ensino que priorize debates sobre questões de cidadania e participação nos espações públicos e mais especifico na forma de monitoramento e fiscalização das contas públicas (GOHN, 2007), (TATAGIBA, 2002) e (CUNHA, 2008).

\subsection{ACCOUNTABILITY NO SETOR PÚBLICO}

Um termo bastante recorrente nas leituras que trata da fiscalização dos recursos público por entes colegiados da sociedade civil organizada e a nomenclatura Accountability, que segundo O’Donnell 2006, corresponde a uma prática de fiscalização exercida pela sociedade, com o objetivo de construir formas de controle sobre os agentes públicos. (BORGES, 2014, p.2)

Gonçalves et al (2011, p.661) define e apresenta a nomenclatura Accountability como sinônimo de conselho, evidenciando seu caráter de responsabilidade sobre prestação de contas do setor público.

Para Gomes (2003, p.58) entende-se accountability como uma suscetibilidade de controle, particularmente ao controle sobre os resultados, executado por mecanismos objetivos e exteriores ao responsável. Para o autor, esta definição reforça a perspectiva de que a accountability está associado 
exclusivamente a uma imposição externa ao indivíduo, abandonando qualquer ligação a uma conotação moral relativa à introjeção de valores público do agente, envolvendo as seguintes premissas: apuração dos resultados, julgamento sobre a adequação as regras previstas, identificação de responsáveis, e sansão aos mesmos

Segundo Carneiro (2002, p.281) o termo accountability pode ser diferenciado sobre os seguintes aspectos: A noção de accountability societal incorpora novos atores, tais como associações, ONGs, movimentos sociais e mídia. Diferentemente das accountabilities horizontal e vertical (que operam basicamente através do mecanismo do voto eleitoral), os agentes da accountability societal não possuem, segundo esta definição, mandato para sanções legais, mas apenas simbólicas, ainda que algumas ações desta forma de controle possam gerar sanções legais.

Assim Carneiro (2002) ressalta que todas as formas de conselhos, seja: locais, estaduais e nacionais, composta por esse papel social e de controle, legalmente constituídas são de fato mecanismos de accountability. Conforme pode observar em destaque:

Portanto, mais do que expressão e mecanismo de mobilização social, os conselhos apontam para uma nova forma de atuação de instrumentos de accountability societal, pela capacidade de colocar tópicos na agenda pública, de controlar seu desenvolvimento e de monitorar processos de implementação de políticas e direitos, através de uma institucionalidade híbrida, composta de representantes do governo e da sociedade civil. (CARNEIRO, 2002, p. 282-283).

\subsection{GOVERNANÇA PÚBLICA}

Segundo Dias (2013, p. 210) a contabilidade aplicada ao setor público, não deve ser vista apenas como uma obrigatoriedade a ser cumprida ou como um instrumento responsável pelo registro de atos e fatos emanados da administração pública, mas sim, ela deve ser vista como uma ferramenta capaz de dar suporte, de forma objetiva e eficaz na verificação dos atos realizados pelo gestor público, respeitando aos princípios emanados da Constituição Federal, tornando-se um mecanismo de governança ao servir de base para a averiguação da forma como vem sendo utilizado o dinheiro público.

$\mathrm{Na}$ área da saúde pública, autores corroboram ao afirmar que a boa governança promove eficácia e eficiência, sobre a gestão dos recursos públicos, permitindo inclusive crescimento econômico e social. Assim, a governança pública vem ao encontro do objetivo de combate ao desperdício de recursos públicos, pois proporcionar uma forma de controle social sobre os detentores do poder (PEREIRA, 2002, 2005), (LEWIS, 2006), e (DIAS ET AL, 2013). 


\subsection{FATORES ASSOCIADOS A IRREGULARIDADES NA GESTÃO DE RECURSOS PÚBLICO EM} SAÚDE

Através de uma pesquisa Dias et al (2013, p.213) busca estudar as correlações de desperdício ativo (com a intenção do gestor e onerar os cofres públicos) e passivo (sem a intenção do ato corruptivo) e suas interfaces em prol da irregularidade na aplicação dos recursos destinados a saúde na esfera municipal. Os achados desta pesquisa corroboram ao evidenciar a inexistência ou fraca atuação do conselho na fiscalização das licitações fracionadas. Com a falta ou fraca atuação do Conselho Municipal de Saúde, as chances de irregularidades relacionadas à gestão passam a serem maiores, pois, não é realizado o acompanhamento devido nas aquisições, que podem acabar sendo realizadas de forma fracionada durante o ano.

Percebesse que a situação de desperdício passivo associado a uma fraca fiscalização, permite aos gestores públicos incorrerem em desperdício ativo, pois os cenários mostram-se favorável para a busca de benefícios pessoas através de investidas em situações de risco punitivo contra o erário público. Assim, os conselhos e seus conselheiros mostram-se como de fundamental importância par combater a proliferação destas práticas. (DI TELLA e SCHARGRODSKY, 2003), (BANDIERA ET AL, 2009) e ( DIAS ET AL, 2013)

Neste sentido, Dias et al (2016) corrobora ao identificar a Governança Corporativa aplicada ao setor público como, uma possível forma de reduzir o desperdício ativo e passivo. Para isso os autores destaca uma serie de 5 ações que visa combater esse desperdício, a saber: o aumento das fiscalizações; uma maior transparência das informações relacionadas aos programas de governo (funcionamento e execução) de forma a tornar a informação efetivamente acessível e compreensível ao cidadão; a implantação de programas de capacitação e motivação do servidor e gestor público, fazendo com que internalizem a importância de sua adequada atuação profissional, buscando paralelamente criar uma cultura de denúncia de irregularidades praticadas no serviço público; a realização de uma análise para verificar se o serviço deve ser mesmo prestado pelo Estado ou terceirizado; e a implantação de novos mecanismos de governança e fortalecimento dos já existentes, como a auditoria da CGU.

\subsection{COVID 19 E A CORRUPÇÃO}

A corrupção ativa ou passiva de recursos públicos sempre foi uma realidade em todas esferas da administração pública brasileira, seja federal, estatual e municipal, no entanto em meio a pandemia do COVID 19, ações mais contundentes marcou a corrupção na empregabilidade dos recursos destinados a saúde pública brasileira.

A crise da saúde pública causada pela pandemia do COVID19, associada crise econômica e turbulências sociais, provocaram a elevação substancial dos gastos públicos com a saúde, fazendo com que 
muitas regras e procedimentos de gestão dos recursos fossem relaxados a fim de atender a emergência que a pandemia requeria na tomada de ações de enfrentamento, ao mesmo tempo que criou muitas oportunidades para ações corruptivas. (GALLEGO ET AL, 2020)

Os autores Michele e Vieyras (2020) Jenkins et al (2020) destacam que seja em uma pandemia, desastre natural, e em emergências econômicas, as ações em resposta tende em acarretar um alto risco corrupção. A exemplo os autores evidenciam os desvios de US\$ 13,5 bilhões de dólares desviados dos países afetados pelo tsunami em 2004 no Oceano Indico, estima-se desvio de 16\% dos recursos destinada a mitigação do desastre pós furacão Katrina, entre outros. Especificamente na América Latina, constatações de corrupção e fraude no enfrentamento destas crises humanitárias são vistos desde 1998 como o furacão Mitch na América Central, em 2010 no terremoto do Haiti, mais recente ao El Niño que atingiu os andes em 2017.

Pesquisadora García (2019), constata em sua pesquisa que o mundo gasta mais que US\$ 7 trilhões em serviços de saúde, deste, cerca de 10 - 25\% é perdido diretamente pela corrupção, valores que excedem o que a Organização Mundial de Saúde (OMS) estima necessário anualmente para cobrir os gastos com a saúde da humanidade até 2030. Além disso a mesma autora destaca:

\begin{abstract}
“A corrupção está embutida nos sistemas de saúde. Ao longo da minha vida - como pesquisadora, trabalhadora de saúde pública e ministra da Saúde do Perú - tenho visto a desonestidade e a fraude enraizadas, mas apesar de ser um dos mais importantes barreiras à implementação da cobertura universal de saúde em todo o mundo, a corrupção raramente é discutida abertamente" (GARCÍA, 2019)
\end{abstract}

No Brasil, país de muitos casos de corrupção noticiado diariamente nos jornais, já era de se espera que oportunistas iria aproveitar da pandemia a das flexibilidades do ordenamento jurídico para afanar os cofres públicos. Passados meses do início dos primeiros casos de coronavírus no Brasil, ações de investigação foram deflagadas por vários órgão e instituições, como Polícia Federal, Ministérios Público, órgãos de controladoria, Polícia Civil, poder judiciário, entre outros, todos no encalço de indícios de malversação do patrimônio público. As investigações se desdobram em praticamente todos estados Brasileiro, na busca por aspectos gerais de desvio de recursos públicos, seja por superfaturamentos de contratos, crimes previstos na lei de licitação, contratação de fornecedores, compra de materiais, contratação de serviços, entre outros. (GOV.BR, BRASIL, 2020)

Os conselheiros de saúde, seja em sua esfera municipal, estadual e federal, não dispõe de pessoas qualificadas, tecnologia e recursos para realizar uma boa fiscalização das contas públicas na área de saúde, carecendo de informações de dados secundários para munirem de informações. Não sendo eles os únicos responsáveis pela fiscalização das contas publicas destinada a saúde, outras instituições como Transparência Internacional - Brasil também tem contribuído com a divulgação e fomento de um 
ranqueamento de estados, capitais e Distrito Federal que tem melhores práticas de transparência em relação aos gastos com a COVID-19 nas contratações emergenciais. (CNS, 2020), (TRANSPARÊNCIA INTERNACIONAL - BRASIL, 2020)

Vale ressaltar que mesmo tendo o portal transparência internacional elencado um conjunto de regras para classificar os estados e capitais mais transparentes, é sabido que outros critérios importantes de analise foram deixados de lado, como o numero de denuncia e investigação sobre desvio de recursos, registro do casos de dilapidação dos recursos de empresas que receberam adiantamento e não entregaram respiradores, entre outras causas

Gaspar, Muhleisen e Brown (2020) acreditam que a atual crise aguçará o foco nas ações de governança, uma vez que seus efeitos devastadores para a população e economia perduraram pelo um longo período. Além disso, os autores ressaltam que os países não podem se dar o luxo de perder recursos públicos, muito menos agora durante e pós pandemia, reforçando ainda a importância de empreender ações contra a corrupção.

\section{CONSIDERAÇÕES FINAIS}

Fato é que a saúde é um direito universal de todos e que temos direito de uso assim como obrigação de fiscalizar. Os espaços dos conselhos de saúde é mais um de outros públicos de que o cidadão pode contribuir diretamente no processo de democratização e cidadania.

Nota que ainda precisa de muitos avanços para que os conselhos sejam de fato um espaço democrático em que todos tenha o mesmo nível informacional, a falta de capacitação para os conselheiros ainda é um entrave para uma boa fiscalização dos recursos públicos. Além disso, discursões ainda devem serem feitas sobre para o conflito de interesse existentes dentro desses espaços, para que não extrapolem o objetivo maior que é a garantia de eficiência na implementação das ações da saúde.

Com essa pandemia do coronavírus (COVID-19) a importância destas ações de accountability e governança torna-se mais necessária, pois com a maior flexibilização das compras públicas dado o estado de calamidade na saúde, fez com que as possibilidades de má administração das contas públicas e corrupção, aumentasse em comparação a período anterior a pandemia.

A historia mostra que a corrupção sempre foi muito presentes em momentos de catástrofes, guerras e outras pandemias, no entanto no caso especifico da pandemia do coronavírus percebe-se que a ingerência desses recursos e a corrupção pode provocar além da dilapidação dos recursos que deveria ser aplicado diretamente nas ações de enfrentamento, como também ser responsáveis pela morte de pessoas que poderia ter sido atendidas pelos serviços não prestados e respiradores não comprados.

Ondem reina vida ainda é possível esperança, muitos trabalhos vêm sendo feitos para melhoria da gestão dos gastos públicos com o COVID - 19, seja pela melhorias nos mecanismos de transparência, seja 
na maior discursão cientifica sobre o tema, seja na maior conscientização esperada para a população, possibilitando uma maior eficiência na implementação de ações práticas, e que de fato permita salvar vidas. 


\section{REFERÊNCIAS}

ABERS, R. N. Inventing local democracy: grassroots politics in Brazil. Lynne Rienner Publishers, 2000.

Andrade, Nilton de Aquino. Contabilidade pública na gestão municipal. 2ed. São Paulo, editora atlas. 2006 ANDRADE, Nilton de Aquino. Contabilidade pública na gestão municipal: métodos com base na LC no. 101/00 e nas classificações contábeis advindas da SOF e STN. 3. ed. São Paulo, SP: Atlas, 2007. xxiv, 327 p. ISBN 9788522447978 (broch.).

BANDIERA, O., Prat, A., \& Valletti, T. (2009). Active and passive waste in government spending: evidence from a policy experiment. American Economic Review, 99 (4), 1278-1308.

Brasil. CONASEMS. Participação social no SUS: o olhar da gestão municipal. Conselho Nacional de Secretários Municipais de Saúde (Brasil). [Brasília]; Conasems; [2009?].

Brasil. GOVERNO FEDERAL. Disponível em: < https://www.gov.br/ptbr/@@search?SearchableText=corrup\%C3\%A7ao+covid+19>Acesso em: 12 de ago. de 2020

Brasil. Ministério da Saúde. Concelho Nacional de Saúde (CNS) Disponível em: <http://conselho.saude.gov.br/ > Acesso em: 12 de ago. de 2020.

Brasil. Ministério da Saúde. Conselhos de saúde : a responsabilidade do controle social democrático do SUS / Ministério da Saúde, Conselho Nacional de Saúde. - 2. ed. - Brasília : Ministério da Saúde, 2013. $28 \mathrm{p}$

Brasil, TCU. Orientações para conselheiros de saúde. 2010

BORGES, Tiago José Gonzaga. Práticas de accountability em administração pública brasileira: existe espaço para este instrumento na saúde pública tupiniquim - via conselho de saúde? Disponível em: < http://www.anpad.org.br/admin/pdf/2014_EnANPAD_APB2272.pdf > Acesso em: 12 de ago. de 2020.

CORREIA, M. V. Que controle social? Os conselhos de saúde como instrumento. Rio de Janeiro: Fio Cruz, 2000.

CARNEIRO, Carla Bronzo Ladeira. Conselhos de políticas públicas: desafios para sua institucionalização. RAP. Rio de Janeiro 36(2):277-92, Mar./abr. 2002

CRACO, P. F.; ALMEIDA, M. C. P. A Participação Popular nas Comissões Locais de Saúde: Mostrando Vidas, Contando Lutas. Revista Brasileira de Enfermagem, v. 57, nº. 02, p. 188-192, 2004.

CUNHA, Sheila Santos. O perfil da participação nos conselhos municipais de assistência social (CMAS) e saúde (CMS) em camaçari (BA): uma análise sobre quem e como participar. Dissertação de mestrado (mestrado em administração) escola de administração. Faculdade de ciências contábeis. UFBA. 2008, $192 \mathrm{f}$.

DIAS, Lidiane Nazaré da silva, et al. Fatores associados ao desperdício de recursos da saúde repassados pela união aos municípios. Cont. Fin. - USP, São Paulo, v. 24, n. 63, p. 206-218, set./out./nov./dez. 2013 DI TELLA, R., \& Schargrodsky, E. (2003). The role of wages and auditing during a crackdown on corruption in the city of Buenos Aires. Journal of Law and Economics, 46 (1), 269-92. 
GAllego, Jorge A; PREM, Mounu; VARGAS, Juan F. Corruption in the Times of Pandemia. Coronavírus and Infectious Disease Research do SSRN. Disponível em: <

https://papers.ssrn.com/sol3/papers.cfm?abstract_id=3600572 > Acesso em: 12 de ago. de 2020.

GARCÍA, Patricia J. Corruption in global health: the open secret. The lancet. 2019. Disponível em:< https://www.thelancet.com/action/showPdf?pii=S0140-6736\%2819\%2932527-9>Acesso em: 12 de ago. de 2020.

GASPAR, Vítor; MÜHLEISEN, Martin; BROWN, Rhoda Weeks. Corruption and COVID-19. Fundo Monetário Internacional (FMI). Disponível em: <

https://www.imf.org/pt/News/Articles/2020/07/27/blog-corruption-and-covid-19> acesso em: 13 de ago. de 2020

GOMES, Eduardo Granha Magalhaes. Conselhos gestores de políticas públicas: democracia, controle social e instituições. Discertação de mestrado ( mestrado em administração) EAESP/FGV, São Paulo, 2003, 110p.

GONCALVES, Andréa de Oliveira; GONCALVES, Rodrigo de Souza and TAVARES, Adilson de Lima. O Olhar dos Conselheiros de Saúde Sobre os Relatórios de Prestação de Contas no Município de Natal (Rio Grande do Norte), Brasil. Saúde Soc. São Paulo, v.20, n.3, p.659-672, 2011

JENKINS, Aram Matthew; KHAGHAGHORDYAN, Kaunain Rahman; JORUM Duri. The costs of corruption during humanitarian crises, and mitigation strategies for development agencies. U4 AntiCorruption Helpdesk. Disponível em: $<$ https://www.u4.no/publications/the-costs-of-corruption-duringhumanitarian-crises-and-mitigation-strategies-for-development-agencies.pdf $>$ Acesso em: 12 de ago. de 2020.

LABRA, Maria Eliana; FIGUEREDO, Jorge ST. Aubyn. Associativismo, participação e cultura cívica. O potencial dos conselhos de saúde. Ciência \& saúde coletiva, 537-547, (2002)]

LEWIS, M. (2006, January). Governance and corruption in public health care systems. [S.1.]: Center for Global Development, Working Paper n. 78. Disponível em:< https://www.semanticscholar.org/paper/Governance-and-Corruption-in-Public-Health-CareLewis/32aae7a1c0811695b46c149794220ca40b5690b5?p2df > Acesso em: 12 de ago. de 2020.

MARTINS, Poliana Cardoso, et al. Conselho de saúde e a participação social no brasil: matizes da Utopia. Physis. Revista de saúde coletiva. Rio de janeiro. 105-121,2008

MICHELE, Roberto; VIERAS, Juan Cruz. How Transparency Can Save Lives in the Coronavírus Crisis. Politics, Business \& Culture in the Americas. Disponível em: $<$ https://www.americasquarterly.org/article/how-transparency-can-save-lives-in-the-coronavirus-crisis/ $\geq$ Acesso em: 12 de ago. de 2020.

PEREIRA, José Matias. Reforma do Estado e controle da corrupção no Brasil. Cadernos de Pesquisa em Administração (USP), 12 (2), 1-17 (2005, abril-junho).

PEREIRA, José Matias. Reforma do Estado e transparência: estratégias de controle da corrupção no Brasil. In: Congreso Internacional Del Clad Sobre La Reforma Del Estado Y De La Administración Pública, 7., 2002, Brasília. Anais... Lisboa: CLAD, 2002. p. 1-22. 
TERRA, Ponto. Conselhos Gestor. Portal eletrônico. Disponível em: http://www.pontoterra.org.br/conselhos/\#: :text=O\%20que\%20\%C3\%A9\%20Conselho\%3F,sociedade $\% 2$ 0civil\%20e\%20Poder\%20P\%C3\%BAblico. _Acesso em: 12 de ago. de 2020.

TRANSPARÊNCIA INTERNACIONAL - Brasil. Disponível em: < https://transparenciainternacional.org.br/ranking/> Acesso em: 12 de ago. de 2020.

WENDHAUSEN, A.; CAPONI, S. O diálogo e a participação em um conselho de saúde em Santa Catarina, Brasil. Caderno de Saúde Pública, v. 18, n. 6, p. 1621- 1628, Rio de Janeiro, 2002. 